

\title{
INSECURE POSITIONS, HETERONOMOUS AUTONOMY AND TOURISM- CULTURAL CAPITAL: A BOURDIEUSIAN READING OF TOUR GUIDES ON BBC WORLDWIDE'S DOCTOR WHO EXPERIENCE WALKING TOUR
}

\begin{abstract}
:
This article contributes towards debates concerning media tourism and tour guiding by using Pierre Bourdieu's (1993) arguments regarding field and capital to analyse performed tour guide identities on BBC Worldwide's Doctor Who Experience Walking Tour in Cardiff Bay. The article pursues three core arguments: firstly, that a Bourdieusian framework provides an enhanced understanding of the insecure positions that tour guides occupy in what is referred to throughout as the tourism field. Secondly, that the divergent pulls between heteronomous and autonomous poles which position tour guides are magnified in officially-located media tours because of the presence of branding and theming discourses. Thirdly, drawing upon empirical data from the Doctor Who tour, that the symbolic capital of official guides involves demonstrations of what is named tourism-cultural capital but such displays do not result in an increase in individualised status as any accrued capital transfers to the institutional level.
\end{abstract}

Keywords:

Media tourism; Doctor Who; tour guides; Bourdieu; field theory; capital; cult geography 


\section{INSECURE POSITIONS, HETERONOMOUS AUTONOMY AND TOURISM- \\ CULTURAL CAPITAL: A BOURDIEUSIAN READING OF TOUR GUIDES ON BBC WORLDWIDE'S DOCTOR WHO EXPERIENCE WALKING TOUR}

\section{Introduction}

The Doctor Who Experience Walking Tour (DWEWT hereafter) is a guided tour offering participants the opportunity to be taken around multiple locations that have been used for filming the globally-popular BBC science fiction programme within the vicinity of Cardiff Bay in the UK. The tour lasts approximately 90 minutes, runs on occasions throughout the year (typically weekends, public and school holidays) and is offered as an optional extra to visitors to the actual Doctor Who Experience (a self-contained themed attraction consisting of an interactive walkthrough section and a museum space; $D W E$ hereafter) for a small additional cost on top of general admission. Operated by BBC Worldwide - the part of the BBC which exploits the commercial possibilities of the Corporation's programmes (Johnson 2012: 76-80) - in conjunction with Cardiff Council, the DWEWT is promoted online as offering 'a journey back through time where you get to see and experience the very locations where Doctor Who was filmed in Cardiff!' (BBC Worldwide 2014: para. 1) in the company of 'our expert tour guides' (BBC Worldwide 2014: para. 1). BBC Worldwide's promotional rhetoric provides the starting point for this article as it represents an attempt to bestow what Pierre Bourdieu (1993) names symbolic capital specifically upon the DWEWT's guides. Symbolic capital is defined as the 'degree of accumulated prestige, celebrity, consecration or honour' (Johnson 1993: 7) assigned to any individual operating in a particular socio-cultural space or, as Bourdieu prefers, field. Yet, tour guiding has been positioned as 'an unglamorous job' (Ap and Wong 2001: 556) which offers 'low social status, low pay, unstable work and 
income' (Mak, Wong and Chang 2011: 1447). Such characterisations (although contestable see below) deny symbolic capital to tour guiding due to its service-based nature and, in a demonstration of how power circulates within what I refer to throughout as the tourism field, its failure to generate sustainable levels of economic capital. Although BBC Worldwide's rhetoric obviously functions as hype for the DWEWT, this disparity between publicity discourses and wider perceptions of tour guiding generates the questions which this article engages with: how can a Bourdieusian framework regarding fields and capital enhance current understandings of the claims to status concerning tour guiding? Given that tour guiding represents a performed identity (Goffman 1959), how might Bourdieu's work be of extra significance to studying guides for official examples of media tourism? Finally, how does applying this approach to guides for the DWEWT indicate where power and status become located on official media-based tours?

To tackle these questions, this article firstly develops a Bourdieusian framework by reviewing previous academic literature on tour guiding and worker identities in themed and/or branded tourist spaces (The Project on Disney 1998; Lukas 2007) - including that explicitly critiquing the Doctor Who Experience in Cardiff (Beattie 2013; Forde 2013; Booth 2015). It then applies these ideas to observational data collected from being a participant on the DWEWT. The article pursues three core arguments: firstly, applying Bourdieusian field theory to tour guiding provides a new way of accounting for the divergent claims to value that surround such identities by demonstrating that these roles are structurally positioned between the competing pulls of what Bourdieu (1993: 37-9) names the autonomous and heteronomous poles. Whilst preceding studies have alluded to the insecure position that tour guiding occupies within the tourism field (Cohen 1985; Weiler and Ham 2001), Bourdieu's ideas allow for the socio-cultural categories underpinning tour guiding's claims to status to be 
better theorised. Secondly, applying this understanding to examples of media tourism layers these arguments by demonstrating that the tensions structuring tour guiding become magnified within these contexts because of wider socio-cultural perceptions concerning branding and theming. However, recognising this point gives rise to addressing instances of what I term here heteronomous autonomy where discourses of branding and agency interrelate and become performed (and potentially valued) in official media tourism contexts. Discussing heteronomous autonomy is significant because, whilst media tourism has 'increase[d] in scale' (Reijnders 2011: 4) and popularity in recent years, few studies have considered the performed identity of tour guides themselves and how their claims to status become negotiated in examples such as the DWEWT where the producing institution provides the tour. Finally, analysing the performed identity of guides on the DWEWT further elucidates these theoretical positions whilst also demonstrating how claims to symbolic capital for the guides arise from demonstrating what I name tourism-cultural capital where established skills concerning tour guiding are performed to participants. However, individualised displays of tourism-cultural capital are rendered hollow because of both its associations with heteronomous autonomy and the tour's lack of opportunities for individualised consecration. Ultimately, the article argues that guides on the DWEWT continue to occupy the insecure position associated with the role within the tourism field but, in this instance, this reflects the lack of opportunity for individually objectifying the capital demonstrated throughout the tour.

Regarding methodological considerations, the empirical data was collected by participating in the DWEWT twice during summer 2014. Although small, the number of studied tours is consistent with previous analyses of guide identities (Howard, Thwaites and Smith 2001) and came about because of this study's retrospective nature. I first approached the DWEWT as a 
'scholar-fan' (Hills 2002: 2) and it was during the tour that I began making notes and taking photographs to record the experience and the guide (Davies 2008: 66). A second DWEWT was then undertaken to corroborate these initial observations but, as the second tour was consistent in terms of length, locations visited and aspects of the guide's performance, no further participation was necessary. Observational techniques were selected partly because of their deployment on preceding studies of tour guiding (see Earl 2008; Knudsen 2010) but also because of the need to recreate my role as 'an inconspicuous bystander' (Davies 2008: 8) on the second tour. It would be naïve to assume that my presence on each tour would not have any impact on the research environment (Davies 2008: 4), however, and so, to demonstrate reflexivity and not posit claims to universality (Davies 2008: 70-2), two points need explicating: firstly, the ensuing arguments come from the perspective of a white, middleclass, British male in his mid-thirties who is a life-long Doctor Who fan. Secondly, the $D W E W T$ discussed throughout relates to that from the period following Matt Smith's departure as the Eleventh Doctor (the DWE itself was closed shortly after in September 2014 and re-themed to accommodate Peter Capaldi's Twelfth Doctor). This point is important as the DWEWT is regularly revised in accordance with new series of Doctor Who. Finally, despite being an organised tour including members of the public, no ethical concerns regarding consent or revealing my identity as a researcher needed addressing. Preceding studies of organised media-based tours have not identified disclosure of identity as an ethical concern (Torchin 2002; Reijnders 2011; Larsen 2015) and one explanation for this is that '[r]esearch in public places - for example observations of public rituals or performances does not require notification of the presence and intent of the researcher' (Davies 2008: 65). As tour guiding has been theorised as a public performance (Holloway 1981: 388), it is classifiable within this category. Additionally, this article focuses primarily on the guide meaning that observation of other tour participants was minimal; when group members are 
mentioned, these align with established ethical perspectives as their identities are generalised and anonymised (Fine and Speer 1985: 76).

\section{Between Autonomy and Heteronomy: A Bourdieusian Reading of Tour Guides}

Tour guiding has received sustained scholarly attention within Tourism Studies but applications of Bourdieu's theories concerning status and the ongoing negotiation of hierarchies within specific socio-cultural fields to these identities has been largely overlooked. One reason for this is that, recognizing how ' $[\mathrm{t}]$ he tourism industry is a distinctively service based one' (Ap and Wong 2001: 552), much preceding research has been industry-facing with a view to developing best practice. These studies have sought to improve the guided tour experience for both tourists and guides by defining the role's parameters for those entering into the profession (Pond 1993) and tackling challenges linked to tour guiding in specific geographical (Ap and Wong 2001; Zhang and Chow 2003; Mak, Wong and Chang 2011) and transcultural (Leclerc and Martin 2004; Salazar 2005) contexts. Alternatively, when analysed theoretically, initial studies of tour guiding used frameworks including social interactionism (Holloway 1981), symbolic interactionism (Goffman 1959) and historical analysis (Cohen 1985) to emphasise the various public-facing social roles which structure tour guiding. Despite establishing the role's overlapping and incongruous requirements, the prominence of these approaches has resulted in issues of status and value pertaining to tour guide identities being infrequently addressed (Earl 2008 and Mak, Wong and Chang 2011 are exceptions).

Bourdieu's (1993) arguments concerning the structure of individual fields were developed to analyse the formation and continuous negotiation of social hierarchies surrounding status, 
prestige and power that operate around individual areas of socio-cultural life (e.g. the production of art and literature) and the social agents that engage in these practices. As suggested above, tour guiding has been positioned as culturally devalued and financiallyunrewarding work, and Betty Weiler and Sam Ham (2001: 262) extend these negative perceptions by summarising further objections to the role:

Current prevailing perceptions and self-perceptions of guides sometimes conjure up images of semi-robotic message repeaters who carry out rigidly orchestrated itinerates and faithfully regurgitate carefully memorized scripts, leaving little to the guide's creative imagination and ingenuity.

By focusing on the deep-rooted discourses that sustain systems of cultural value, Bourdieu's (1993: 38) work provides a way of accounting for what underpins these dismissals as the concepts which are implied here align tour guiding with what he names the 'heteronomous pole'. The heteronomous pole provides an overarching structural influence upon the status afforded to positions in each field and is where individuals (named 'agents') 'bec[o]me subject to the ordinary laws prevailing in the field of power, and more generally in the economic field' (Bourdieu 1993: 38). In other words, those associated with the heteronomous pole are denied symbolic capital within individual fields partly because the positions they occupy (e.g. as tour guides) carry deep-rooted commercial associations. Dismissals of tour guiding, and guided tours more generally, 'as "cattle," "herding," and "automation"” (Quiroga 1990: 187), as well as broader systems of value within the tourism field which assign status to 'avoiding the package holidaymaker, [and being]... an educated traveller' (Urry and Larsen 2011: 108), provide further evidence of how entrenched these meanings are. From this perspective, tour guides are devalued through being located along commercial 
discourses and carrying connotations of formulaic, standardised and (financially) unrewarding labour. All of which assigns the role reduced levels of symbolic capital by aligning tour guiding with heteronomous principles (see also Holloway 1981: 381-2; Cohen 1985: 18)

Yet, these dismissals represent a simplification of tour guiding's position and status within the tourism field. Complicating perceptions of repetitive, commercially-rooted identities, tour guiding has also been defined as a multi-faceted role which requires agents to demonstrate multiple competencies:

From the tourists' perspective, they are the "pathfinders," "animators," "tour leaders," and "mentors" ...As employees of tour operators, they are the "spokespersons" representing the image and reputation of the company ... and the "ambassadors" entrusted with the public relations missions of the destination. (Mak, Wong and Chang 2011: 1442)

Focusing on the ambassadorial role alludes to a way that tour guiding's status can be potentially revalued because John Urry and Jonas Larsen (2011: 81) have argued that leading tours can provide greater opportunities for demonstrations of autonomy than other (service) industry roles. Given that the position and status held by any agent in a field is relational and dynamic (Johnson 1993: 6), this suggests that tour guiding can provide opportunities for accruing symbolic capital and prestige. This is because a guide's public relations responsibilities can include 'bend[ing] scripts' (Urry and Larsen 2011: 81) by adapting their performance to the requirements of individual groups. Such demonstrations would, from a Bourdieusian perspective (1993: 38), accrue greater status for individual guides by shifting 
them towards the 'autonomous pole' where 'specific capital unique to that field' (Benson and Neveu 2005: 4) generate status. As evidenced below, the forms of field-specific capital that can align guides with the autonomous pole include demonstrations of tourism-cultural capital where individualised competencies can be demonstrated. The autonomous pole exists in continual tension for dominance with its heteronomous equivalent and the primacy of one over another at any historical moment is indicative of the location of power across all fields. By performing a role that permits demonstrations of autonomy within the tourism field, tour guiding generates possibilities for accruing symbolic capital and gaining individualised status.

Although tour guiding's ambassadorial role might enable displays of autonomy, this does not equate to complete individuality; as Erik Cohen (1985: 15) argues, guides remain 'intended either to impart or maintain a desired "tourist image" of the hosts setting'. Instead, the complexity of the roles associated with tour guiding indicates it is a position which continually negotiates between the divergent pulls of the autonomous and heteronomous poles, leading to the role's insecure position within the tourism field. What subsequently becomes of interest is how these tensions play out across different instances of tour guiding. Exploring this point further, the next section critically reviews previous studies of official media tourism and its workers, arguing that these constraints become magnified within these contexts.

\section{Magnifying Tensions: Official Media Tourism and Heteronomous Autonomy}

Urry and Larsen (2011: 102-7) have used a Bourdieusian approach to account for media tourism's recent rise in popularity by relating this to the evolution of the consumer society 
and the emergence of new lifestyle groups seeking to distinguish themselves from the tastes of their predecessors and peers. In contrast, media-based tour guiding has received only sporadic attention and has avoided applying Bourdieu's ideas. Stijn Reijnders (2011: 8) mentions tour guides in passing as part of his argument concerning how filming locations function as 'lieux d'imagination ...[or] physical locations, which serve as a symbolic anchor for the collective imagination of a society.' For Reijnders (2011: 15), tour guides assist in highlighting the significance of places 'as locations where the symbolic difference between these two concepts [e.g. 'fiction' and 'reality' - RPG] is ...(re-)constructed by those involved' such as in Dracula-derived tours of Romania where 'guides ... use history as an authorative argument about what is 'real' and 'unreal' about Dracula.' (Reijnders 2011: 99) By addressing the guide's mediatory role in adopting 'rational' discourse and addressing the symbolic gap between fictional worlds and their 'real' spatial referents, Reijnders (2011: 8893) approaches tour guiding through 'the discursive binary of authenticity and artifice' (Torchin 2002: 259) that has prevailed in both wider studies of media tourism and specific mentions of media tour guides (see Beeton 2005: 111-2).

Elsewhere fleeting assessments of tour guide performances have been made regarding unofficial media-based tours and, through doing this, have alluded to the presence of scripted performances and organisational brand values (Akass and McCabe 2004; Nelson 2004). Approached from a Bourdieusian perspective, these studies are significant for two reasons: firstly, the evaluations of performance offered are indicative of how academics can act as ‘consecrating agents' (Bourdieu 1993: 11) by bestowing or denying symbolic capital upon their guides. Secondly, these studies allude to structuring tensions between the heteronomous and autonomous poles. Sue Beeton's (2005: 110) discussion of a guide's performance on a New York bus tour of screen media locations further explicates these issues: 
our guide commented (after a rather poor joke) 'Don't blame me, I just say what they tell me to ...' while waving a sheet for us all to see. This is in contrast to many of the tour companies that I have either worked with or had a professional relationship with, where the guides are encouraged to develop this own 'scripts' and put their own personalities into them.

This anecdote suggests how tensions between individualised agency and organisational structures play out within specific (media) tours - a concern which is arguably magnified when official examples such as the DWEWT are considered because of branding's centrality to the contemporary television industry (Johnson 2012). Thus, despite opportunities for demonstrating autonomy being part of tour guiding, branding discourses recall preceding studies of officially-located media tourism such as theme park workers. Scott Lukas (2007: 184) has commented that theming and adherence to brand values can be read as 'a form of discipline and social control' which reduces an individual's role to that of 'repetitive and service-based jobs' (The Project on Disney 1998: 117). Employees of official media brands operating within the tourism sector such as Disney have been denied symbolic capital and aligned with the heteronomous pole because of the 'commodified', and hence 'inauthentic' (Lukas 2007: 183), nature of their performed identities.

Such attitudes towards official media tourism are identifiable in academic appraisals of the DWE. Paul Booth (2015: 106), argues that 'official tour[s] lack... the sense of authenticity that a nonofficial (or fan-created) media tour might engender' because 'industry-created fan destinations ... serve as incongruous refocalisations of the affective work of fans, exemplifying and highlighting commercial aspects of the media text important to fandom.' 
(Booth 2015: 101). This position has also been suggested in Teresa Forde's (2013: 66) critique of the $D W \mathrm{E}$ that 'visitors are initially identified as shoppers who have wandered into the place' and then extended by Melissa Beattie (2013: 186) who, when discussing a predecessor to the DWEWT (an audio recording which fans could listen to as they toured areas close to the $D W E$ ), posits that:

commodification also channels and controls present-day access for fans ...the BBC's recorded tour of filming locations ...follow set routes in a set order, offering ...A. Arthur Darvill's voice as a guide ...This is a very different experience to walking around Cardiff on one's own (or with other fans); although there may be a certain degree of hierarchy in fan-based groups (such as a fan-resident or frequent fan-tourist being relied upon for directions), in most cases interpretation from 'above' would not occur. Fan-based tours also call for far less economic capital than professional commercial events, while even the BBC's fan (public) service tour requires an mp3 player or other audio device.

These statements recurrently combine commercially-rooted discourses with critiques of the structured and formulaic nature of officially-controlled media tourism. Such dismissals align these tours and attractions with Bourdieu's heteronomous pole via echoing the aforementioned perceptions and devaluations of organised tours more generally. What's more, these negative attitudes exist in contrast with analyses of self-organised examples of media-tourism which have gained connotations of authenticity and value because of their assumed independence, spontaneity and, crucially, autonomy (see Hills 2002: 145-51; Brooker 2005, 2007; Larsen 2015). 
However, each of these studies overlooks detailed analysis of the performed role of tour guides within official media tourism contexts and the insights that applying a Bourdieusian perspective can provide. For example, given the myriad roles that tour guiding involves, what forms of capital are demonstrated on official tours? Additionally, as symbolic capital can be accrued at institutional or individual levels, how is this constructed and ultimately located (e.g. institutionally or individually) on a tour like the DWEWT? Writing in relation to (nonmedia) guided tours, Aviva Geva and Arieh Goldman (1991: 183) have questioned whether, 'the company offering the tour is not fully credited with the success of the guide and with the favourable evaluation of the tour's performance'. This alludes to how forms of capital identifiable on a tour can be objectified and converted into symbolic capital. Additionally, what opportunities for demonstrating autonomy are possible on an officially-located example like the DWEWT? As The Project on Disney's (1998: 112) study demonstrates:

For many workers - often the same people who complain bitterly - the park's magic is quite magical, and is so in a way that, almost too perfectly, encourages in them a sense of their own autonomy and distance from Walt Disney Co., the corporate monolith, even as it requires them to perform the tasks for which too many of them are so poorly paid.

Although focused upon workers' self-perceptions, this suggests that oppositions between the heteronomous and autonomous poles can become blurred as employees adhere to brand values at the same time as interpreting this alignment as demonstrating agency. This is a possibility that field theory recognises as Bourdieu (1993: 127) argues that 'Within a single universe one always finds the entire range of intermediaries between works produced with reference to the restricted market on the one hand, and works determined by an intuitive 
representation of the expectations of the widest possible public on the other.' In other words, within individual fields such as that concerning tourism there exists at any moment a range of intermediary positions where the forms of capital associated with both poles interrelate. Recognising this point raises the possibility of official media tourism workers demonstrating what I would call heteronomous autonomy as their performances become tailored to the needs of specific tourist groups at the same time as staying 'on brand'. The remainder of this article explores the questions raised here by deploying observational analysis towards guides' performed identities on the DWEWT.

\section{Symbolic and Tourism-Cultural Capital: Analysing the DWEWT}

Both $D W E W T$ s undertaken for this study were led by different guides. However, although their gender varied on each occasion (one was male, the other female), other similarities were noticeable. These included their estimated age (both were in their early-to-mid-twenties) and aspects of their self-presentation. The latter was especially noteworthy as demonstrations of symbolic capital were immediately foregrounded through wearing branded clothing such as jackets, fleeces, polo-shirts, lanyards and individualised ID badges bearing the BBC logo, as well as an ear-piece and walkie-talkie which connected them to the $D W E$. If elements including 'insignia, clothing, posture, and speech patterns provid[e] ...clues for the audience' (Holloway 1981: 390) about a guide's (performed) identity and status, those constructed for $D W E W T$ guides are high in symbolic capital. This is because guides immediately foreground their distinction in comparison to tour participants by displaying markers of a professional identity and making their institutional affiliation explicit. 
The guide's self-presentation can be read from various perspectives. On the one hand, their constructed identity recognises tourist preferences for 'experienc[ing] the pre-imagined local' (Salazar 2005: 641). Trading upon the DWEWT's official status, and the BBC's reputation as 'a genuine international player ... [and] a public service broadcasting icon in the UK' (Nelson 2007: 68), means that institutionally-located symbolic capital becomes bestowed upon the guide. Consequently, it suggests to participants that what follows is an authentic experience provided by an official BBC employee. On the other, the guide's self-presentation can also be aligned with institutional ideologies concerning BBC Worldwide and its relationship with the BBC. BBC Worldwide's guidelines state that any product it produces or licenses, such as the $D W \mathrm{E}$ and $D W \mathrm{EWT}$, must 'not jeopardise the good reputation of the $\mathrm{BBC}$ or the value of the BBC brand' (BBC Worldwide 2015: 34). Constructing DWEWT guides as professional BBC employees adheres to this policy as it suggests (albeit falsely) a professional, industriallylocated identity for the guide which generates distinction for them. ${ }^{1}$ What's more, the guide's self-presentation reflexively acknowledges the importance of introductions for guides as it is during 'these opening moments ... [that] their audience is appraising them and searching for clues that will assist them to interpret their situation.' (Holloway 1981: 389). By immediately foregrounding their symbolic capital, these displays connote the prestige of both the tour and the guide set out in publicity discourses.

\footnotetext{
${ }^{1}$ Workers at the $D W \mathrm{E}$, including those that operate as guides for the $D W \mathrm{EWT}$, are employees of BBC Worldwide rather than BBC media workers. This point became clear during the second tour when the guide was asked about their involvement in making the series. Sheepishly, the guide replied that such opportunities only arose through routes of work experience and taking up the position of a floor runner.
} 
Alternatively, if read in terms of cultural and symbolic power, the guide's self-presentation recalls strategies identified in previous studies of official media tourism as their clothing constructs an '[i]nvisible, implied boundary' (Couldry 2000: 107) between themselves and tour participants. Whereas the guide's identity denotes their proximity to media 'production' spheres, this contrasts with that of group members who are instead lacking in such forms of symbolic capital and so positioned as inferior media 'consumers'. Tour participants are thus invited to enjoy a temporary increase in their own media-derived symbolic capital by 'buy[ing] into' the tour/guide's official status (Earl 2008: 45) and the privileged access being granted to the spectacular world of producing Doctor Who in Cardiff (Sandvoss 2005: 50-2). Such temporary elevations indicate the type of liminal experiences associated with wider practices of self-organised media tourism which Will Brooker (2005) has discussed.

Yet, analysing the guide's self-presentation using a Bourdieusian perspective demonstrates how such displays generate insecurity surrounding the guide's individualised claims to status. This is because the symbolic capital displayed through their presentation as a BBC employee can be read as a variation upon what Aeron Davis and Emily Seymour (2010: 743; original emphasis) name "institutionalized media capital" within the tourism field. For Davis and Seymour (2010: 743), writing on the political field, this form of capital 'is associated with the position of an individual within a political party or state institution' and so refers to how individual agents can accrue status as a result of appearing in the media as institutional representatives. Applying this concept to guides for the $D W E W T$ requires a little adaptation because, instead of referring to media exposure, the concept can arguably be extended to include working for media institutions in a non-media field. Nevertheless, one consequence of the institutionalised media capital that $D W E W T$ guides embody is that their individualised claims to distinction are insecure because their status is located solely at the institutional 
level. What's more, the guide's embodied symbolic capital is potentially devalued further because of the connotations of theming which arise. Lukas (2007: 186) argues that within themed spaces 'costumes ... [are] connected to the theme, and ... employees perform in a way consistent with the costumes, theming, and symbolic associations of' their themed identity. The guide's clothing therefore implies a lack of individuality, which denies them symbolic capital, as their identity has become subsumed to branding practices and 'reproducing the same commodified ... charm' (The Project on Disney 1998: 125) required by official themed attractions.

Although Bourdieu (1998) indicated that symbolic capital can be a distinct form, he also suggested that it can be 'an aggregate reflection of other capital forms' (Davis and Seymour 2010: 741) which individual agents have accumulated. This latter understanding of symbolic capital applies to guide performances on the DWEWT as individualised claims to status were supported by ongoing demonstrations of an additional form of capital that I have named tourism-cultural capital. Before discussing tourism-cultural capital in an applied manner, it is necessary to define and defend the concept and outline its strengths against previous overlapping theoretical ideas. Tourism-cultural capital refers to guides displaying the competencies, or “"performative labour"” (Urry and Larsen 2011: 78), expected of the role by ensuring that 'the right kind of experience for visitors [becomes constructed] through interpersonal interactions' (Dicks 2008: 442). The neologism therefore refines Bourdieu's concept of cultural capital by re-locating this within the tourism field and adapts it to apply to the competences which guides should demonstrate whilst performing their role(s). Cultural capital 'concerns forms of cultural knowledge, competences or dispositions' (Johnson 1993: 7) and can include 'educational credentials, technical expertise, general knowledge, verbal abilities and artistic sensibilities' (Benson and Neveu 2005: 4). The term thus represents a 
legitimate way of distinguishing between individual and/or class tastes within a social structure (e.g. those from higher social classes would demonstrate greater amounts of this through choosing to visit the opera over watching television). In contrast, when transposed to an alternative field, cultural capital could be read as the set(s) of professionally-focused dispositions that agents must accrue and display to take up specific positions within that field This is because, different to Bourdieu's (1993: 58) ideas regarding the established rules of operating in a particular field (e.g. understanding how to join the tourism field and build a career within this socio-cultural space) named 'doxa', cultural capital refers to the forms of knowledge that agents must display to establish and maintain their position within a particular field. Just as someone could not successfully take up a position within the art or literary field without knowledge and understanding of established formal traditions and interpretive dispositions, an agent could not take up a position as a tour guide within the tourism field without knowledge and mastery of the expected behaviours that the role necessitates. Tourism-cultural capital therefore captures the field-specific competences that individual agents are expected to display with a view to successfully operating, and gaining distinction, within the tourism sector.

The concept of tourism-cultural capital also better captures the competencies expected of tour guides than previous attempts at developing a Bourdieusian understanding of the role such as Mak, Wong and Chang's (2011: 1444) suggestions regarding '[t]he habitus of the guiding profession'. Defined as the set 'of idealized and realized dispositions affecting tour guides and guiding practices' (Mak, Wong and Chang 2011: 1444), on first impressions the tour guiding habitus similarly suggests required social, cultural and historical competencies. On closer inspection, though, conceptualising these as a habitus suggests a misreading of the term as it overlooks key aspects of Bourdieu's concept. For Bourdieu, habitus is the 
'predispositions, assumptions, judgements, and behaviours' (Benson and Neveu 2005: 3) accumulated by individual agents from an early age which helps determine their levels of embodied capital and the fields they take up positions within. The habitus is therefore rooted in class identity, transposable across different spheres, and, crucially, endures and mutates throughout an individual's life (Johnson 1993: 5). Whilst preceding studies of tour guiding have implied that the profession is a traditionally middle-class occupation (Holloway 1981: 393), these wider social determinants are not directly addressed by Mak, Wong and Chang (2011), resulting in their concept of a tour guiding 'habitus' being under-theorised. Whilst it is undeniable that tour guiding requires agents to demonstrate shared attributes and dispositions, the concept of tourism-cultural capital allows for these to be considered as a set of competencies that an individual can learn rather than a set of 'structured structures' (Johnson 1993: 5) which agents are born into and impact upon themfrom an early age.

When applied to the DWEWT's guides, tourism-cultural capital can be understood as a multifaceted form which was demonstrated in myriad ways throughout the tour with a view to building the individualised symbolic capital of each guide. One way that it became immediately displayed at the start of each tour was by an ice-breaking exercise where different levels of enthusiasm for Doctor Who were gauged. Each group was asked how excited they were to be visiting filming locations for the programme, how much they enjoyed the series, its spin-offs (e.g. Torchwood (BBC 2006-11) and The Sarah Jane Adventures (BBC 2007-11)) and stablemates (e.g. Sherlock (BBC 2010- ) and Wizards vs. Aliens (BBC 2012- )) and, jokingly, which members of the group had been dragged along begrudgingly by partners, friends or siblings. Such an exercise is indicative of pre-established expectations that ' $[\mathrm{t}]$ he guide is supposed to keep his party in good humour and in high morale through pleasant demeanour and occasionally jocular behaviour.' (Cohen 1985: 12-13). By 
demonstrating these skills during the tour's opening exchanges, the guide quickly showcased their 'group management and leadership skills' (Weiler and Ham 2001: 256) to participants and so made bids for distinction via tourism-cultural capital.

Additional displays of tourism-cultural capital were identifiable in different ways across both tours: for example, at one point during the second tour the group stopped outside of the Welsh Assembly Government's Senedd building (which featured in 'The Lazarus Experiment' (2007) and 'The Bells of St John' (2013)), and the guide's commentary was suddenly interrupted by a small non-Western child asking a question about the Doctor's sonic screwdriver. The guide abruptly stopped their commentary, and addressed the child directly, before recommencing their outline of the location's significance to Doctor Who. The guide's attentiveness drew approving smiles from the group and is indicative of how demonstrating ‘[c]ross-cultural awareness' (Weiler and Ham 2001: 256) and creating an inclusive atmosphere are core competences for tour guides which generate positive evaluation (Zhang and Chow 2003: 86; Leclerc and Martin 2004: 193). Demonstrating sensitivity towards a younger group member is thus readable as an additional opportunity for showcasing embodied tourism-cultural capital which assists in maintaining the guide's individualised levels of symbolic capital during the tour.

Alternative codings of tourism-cultural capital were also displayed on the first tour when group members enquired about the whereabouts of filming locations not featured on the tour. One participant asked about where a sequence involving the Tenth Doctor (David Tennant) and the Master (John Simm) from 'The End of Time: Part One' (2009) was filmed. The guide responded accurately and promptly to the question but also demonstrated care for the tourist's safety beyond the tour's parameters by warning that the location was not accessible to the 
public for health and safety reasons. This response was significant because tourism-cultural capital became constructed in a layered manner. Firstly, the guide's concern for individual participant's safety after the tour alluded to the professional competencies expected of guides to provide cautionary advice about the surrounding environment (Weiler and Ham 2002: 54). Secondly, individualised claims to tourism-cultural capital were enhanced as ' $[\mathrm{t}] \mathrm{he}$ dissemination of correct and precise information is by many considered to be the kernel of the guide's role' (Cohen 1985: 15). In this instance, the ability to provide additional information about locations not on the tour evidenced the knowledgeability, and hence status, of the DWEWT guide. The guide's tourism-cultural capital thus became enhanced by fusing itself with high levels of fan-orientated subcultural capital via showing that they were "'in the know"' (Thornton 1995: 11) about the whereabouts of multiple Doctor Who filming locations around Cardiff Bay. Previous studies of self-organised fan tourism have posited that identifying filming locations requires 'specialist knowledge and fan investment' (Brooker 2007: 436). Responding to individual participant's requests for further information shows high levels of subcultural capital and converts this in to tourism-cultural capital by performing their identity as knowledgeable about wider aspects of Doctor Who's filming in and around Cardiff Bay.

These examples of tourism-cultural capital arguably open up multiple avenues for further scholarly discussion. For example, the shift of subcultural capital originating within a mediabased fan community to representing status and authority within the tourism field connects with debates concerning mediatization which examine how the media's 'spreading influence ...across more and more separate fields' (Couldry 2014: 59) reorganises power and status within individual contexts. Although highly relevant to this article's themes, and indicative of future trajectories for Bourdieusian-inspired research on media tourism, exploring such 
debates here would nevertheless divert away from the preliminary theorising of the positions and status afforded to guides for official media-based tours like the DWEWT being undertaken. Alternatively, these demonstrations of tourism-cultural capital can be used to analyse how and where symbolic capital becomes ultimately constructed and located for $D W E W T$ guides. On the one hand, the ongoing and varied displays of tourism-cultural capital mentioned can be read as individualised claims to symbolic capital as in each instance the guide demonstrates capabilities associated with the autonomous pole by and moving away from associations that tour guides are robotic pre-scripted mouthpieces (Dicks 2008: 443). Instead, reacting to participants in an ad hoc manner echoes Cohen's (1985: 14) discussion of autonomy in tour guiding:

The guide may select "objects of interest" in accordance with his personal preferences and taste, his professional training, the directions received from his employer or from the tourist authorities, or the assumed interests of his party. In any case, his selection will, to a considerable extent, structure his party's attention during the trip

The DWEWT does not grant complete autonomy to its guides with regard to the route because, whilst the second trip was slightly shorter than the first, both trips visited the same locations. Nevertheless, their ability to solicit questions and respond to individual requests for information shows sensitivity towards the party's needs and so functions as bids for symbolic capital via exhibiting tourism-cultural capital. On the other, though, it is arguable that the bids for symbolic capital connoted by these examples remain largely unconverted as they occur at the individual level and are denied opportunities for wider consecration beyond the tour's immediate parameters. The guide's displays of tourism-cultural capital are therefore readable what I would call non-objectifiable individualised symbolic capital. Although 
recurrent displays of competence generated sustained positivity towards their performance, the tour's end (where participants return to the $D W \mathrm{E}$ building) generated no opportunities for the symbolic capital accrued through their performance to become tangibly objectified. This was best exemplified after the second tour when, during my trip around the $D W E$ 's museum spaces, I saw the guide fulfilling other roles such as monitoring guest behaviour around the props and attractions. This suggests that the individualised symbolic capital which they had generated during the DWEWT does not alter the status and position of tour guiding within official examples of media tourism despite being enhanced by the BBC's reputational prestige.

The individualised symbolic capital bestowed on the guide throughout the tour via demonstrations of tourism-cultural capital is also further hollowed because it can be read as exemplifying heteronomous autonomy. BBC Worldwide's (2015: 2) institutional ideologies require that 'all activities are conducted in a way that is consistent with BBC standards and values.' Doctor Who currently constitutes a 'flagship brand with a global reach' (Beattie 2013: 184) for the $\mathrm{BBC}$ at the same time as being a cornerstone of $\mathrm{BBC}$ One's public service requirements domestically through operating as “consensus” audience grabber' (Hills 2010: 211) across multiple delivery platforms. Demonstrations of tourism-cultural capital like commenting on the range of interest towards the programme amongst group members, being attentive towards younger tour participants or, as was the case with the second tour, closing down the questions from over-enthusiastic fans, are all readable as institutionally-located strategies that keep the DWEWT 'on brand' as an attraction seeking mainstream-cult appeal (Hills 2010: 218-26) rather than singularly addressing cult fans. Read from this perspective, the guide's performance is indicative of William Gordon's (2002: 18) argument that employees must 'exercise "brand manners" that govern the way' individuals interact with 
members of the public. As Gordon (2002: 20) continues, '[n]o matter who the customer interacts with ...they should be treated with the same good brand manners the company wishes to symbolise'. Applying these positions to the DWEWT, displays of tourism-cultural capital which became converted into non-objectified, but individualised, symbolic capital simultaneously fulfil institutional requirements to uphold the brand values of Doctor Who and subsequently the symbolic capital of the BBC. This locates the guide's performance as embodying heteronomous autonomy within the tourism field as, despite demonstrating the competencies expected of tour guiding at an individual level, these displays ultimately work to reinforce both Doctor Who and BBC Worldwide's brand values. Forms of capital associated with the autonomous and heteronomous poles interrelate in these instances as demonstrations of tourism-cultural capital highlight the guide's individualised agency but these demonstrations nevertheless remain readable as offering support for the BBC's reputation. Thus, whilst the $D W E W T$ provides opportunities for guides to demonstrate autonomy and generate forms of individualised symbolic capital, the status produced ultimately becomes located at the institutional level as guides lack opportunities for individual consecration and, following the tour's cessation, return to performing other tasks within the $D W E$ 's spaces.

\section{Conclusions}

This article has used Bourdieusian field theory to analyse the performed identity of tour guides and demonstrated that employing these ideas can provide tourism scholars with an enhanced understanding of the divergent claims to status surrounding the role. This is because the complex nature of tour guiding positions these identities between principles of heteronomy and autonomy. Such tensions then become magnified in relation to official examples of media tourism because of the heightened presence of brand discourses. 
However, this article has demonstrated the need to consider issues including the degree to which principles of heteronomy and autonomy play out on individual tours as well as the possibility for instances of heteronomous autonomy where commercial concerns such as theming and demonstrations of agency align. Additionally, the article has argued for considering the forms of capital that become constructed on official examples of media tourism, how those forms of capital become translated into symbolic capital and where they are located and objectified. Regarding the DWEWT, it was demonstrated that the guides immediately foreground their institutionalised media capital at the start of the tour through costuming. Over the course of the tour, though, guides frequently demonstrate their levels of what I have named tourism-cultural capital by maintaining an inclusive atmosphere, answering questions and demonstrating sensitivity towards the requirements of individual groups. This does not necessarily result in an increase in status for the guide, however, as certain aspects of their performance exemplify heteronomous autonomy (e.g. maintaining the 'family', rather than 'cult', appeal of Doctor Who) whilst no opportunities for consolidating, converting or objectifying their tourism-cultural capital into individualised symbolic capital arise. Consequently, guides for the DWEWT echo the wider status and perception of the role as their agency generates insecure positions for them whilst reinforcing the positive image of the $\mathrm{BBC}$ within the tourism field.

The arguments and approach developed throughout this article point towards how Bourdieu's ideas can provide new insights into understanding the status and value afforded to different forms of employment within the tourism field and that further mapping of this imagined socio-cultural space is required. For example, future studies could compare guides on the $D W E W T$ with other examples of official and unofficial media tourism within a specific geographical area or across different regional, national and international contexts. 
Alternatively, further research could analyse how the status afforded to different forms of (guided) tourism are positioned within the tourism field to better understand the variety of positions available and their relationship to systems of cultural power. Whichever path is taken, though, a Bourdieusian perspective provides an insightful guide.

\section{References}

Akass K and McCabe J (2004) Carried away in Manhattan. In: Akass K and McCabe J (eds) Reading Sex and the City. London: I.B. Tauris, pp.234-6.

Ap J and Wong KKF (2001) Case study on tour guiding: professionalism, issues and problems. Tourism Management 22(5): 551-563.

BBC Worldwide (2014) Doctor Who Experience Walking Tour dates extended. Available at: http://www.doctorwho.tv/whats-new/article/doctor-who-experience-walking-tour-datesextended/ (accessed 29 August 2014).

BBC Worldwide (2015) Annual review 2014-2015: World class - building the BBC and UK creative industries around the world. Report, BBC Worldwide, UK.

Beattie M (2013) The 'Doctor Who Experience' (2012- ) and the commodification of Cardiff Bay. In: Hills M (ed) New Dimensions of Doctor Who: Adventures in Space, Time and Television. London: I.B. Tauris, pp.177-191.

Beeton S (2005) Film-Induced Tourism. Clevedon: Channel View Publications. 
Benson R and Neveu E (2005) Introduction: Field theory as a work in progress. In: Benson R and Neveu E (eds) Bourdieu and the Journalistic Field. Cambridge: Polity Press, pp. 1-25.

Booth P (2015) Playing Fans: Negotiating Fandom and Media in the Digital Age. Iowa City: University of Iowa Press.

Bourdieu P (1993) The Field of Cultural Production: Essays on Art and Literature.

Cambridge: Polity Press.

Bourdieu P (1998) On Television and Journalism. London: Pluto Press.

Brooker W (2005) The Blade Runner experience: Pilgrimage and liminal space. In: Brooker W (ed) The Blade Runner Experience: The Legacy of a Science Fiction Classic. London: Wallflower Press, pp. 11-30.

Brooker W (2007) Everywhere and nowhere: Vancouver, fan pilgrimage and the urban imaginary. International Journal of Cultural Studies 10 (4): 423-444.

Cohen E (1985) The tourist guide: the origins, structure and dynamics of a role. Annals of Tourism Research 12(1): 5-29.

Couldry N (2000) The Place of Media Power: Pilgrims and Witnesses of the Media Age. London: Routledge. 
Couldry N (2014) When mediatization hits the ground. In: Hepp A and Krotz F (eds)

Mediatized Worlds: Culture and Society in a Media Age. Basingstoke: Palgrave Macmillan, pp.54-71.

Davies CA (2008) Reflexive Ethnography: A Guide to Researching Selves and Others, $2^{\text {nd }}$ Edition. London: Routledge.

Davis A and Seymour E (2010) Generating forms of media capital inside and outside a field: the strange case of David Cameron in the UK political field. Media, Culture and Society 32(5): 739-759.

Dicks B (2008) Performing the hidden injuries of class in coal-mining heritage. Sociology 42 (3): 436-452.

Earl B (2008) Literary tourism: Constructions of value, celebrity and distinction. International Journal of Cultural Studies 11 (4): 401-417.

Fine EC and Speer JH (1985) Tour guide performances as sight sacralization. Annals of Tourism Research 12(1): 73-95.

Forde T (2013) 'You anorak': The Doctor Who Experience and experiencing Doctor Who. In: Booth P (ed) Fan Phenomena: Doctor Who. Bristol: Intellect, pp.72-82.

Geva A and Goldman A (1991) Satisfaction measurement in guided tours. Annals of Tourism Research 18(2): 177-185. 
Gordon W (2002) Minding your brand manners: every employee can be an ambassador for your brand. Marketing Management 11(5): 18-20.

Hills M (2002) Fan Cultures. London: Routledge.

Hills M (2010) Triumph of a Time Lord: Regenerating Doctor Who in the Twenty-First Century. London: I.B. Tauris.

Holloway JC (1981) The guided tour: A sociological approach. Annals of Tourism Research 8(3): 377-402.

Howard J, Thwaites R and Smith B (2001) Investigating the roles of the indigenous tour guide. The Journal of Tourism Studies 12(2): 32-39.

Johnson C (2012) Branding Television. London: Routledge.

Johnson R (1993) Editor's introduction: Pierre Bourdieu on art, literature and culture. In: Bourdieu P (1993) The Field of Cultural Production: Essays on Art and Literature. Cambridge: Polity Press, pp. 1-25.

Knudsen BT (2010) The past as staged-real environment: Communism revisited in The Crazy Guide Communism Tours, Krakow, Poland. Journal of Tourism and Cultural Change 8 (3): $139-153$. 
Larsen K (2015) (Re)Claiming Harry Potter pilgrimage sites. In: Brenner LS (ed) Playing Harry Potter: Essays and Interviews on Fandom and Performance. Jefferson: McFarland, pp.38-54.

Leclerc D and Martin JN (2004) Tour guide communication competence: French, German and American tourists perceptions. International Journal of Intercultural Relations 28(3-4): 181-200.

Lukas SA (2007) How the theme park gets its power: Lived theming, social control, and the themed worker self. In: Lukas SA (eds) The Themed Space: Locating Culture, Nation and Self. Lanham: Lexington Books, pp.183-206.

Mak AHN, Wong KKF and Chang RCY (2011) Critical issues affecting the service quality and professionalism of the tour guides in Hong Kong and Macau. Tourism Management 32(6): 1442-1452.

Nelson A (2004) Outsiders in the city. In: Akass K and McCabe J (eds) Reading Sex and the City. London: I.B. Tauris, pp.231-3.

Nelson R (2007) State of Play: Contemporary “High-End” TV Drama. Manchester: Manchester University Press.

Pond KI (1993) The Professional Guide: Dynamics of Tour Guiding. New York: Van Nostrand Reinhold. 
Quiroga I (1990) Characteristics of package tours in Europe. Annals of Tourism Research 17(2): 185-207.

Reijnders S (2011) Places of the Imagination: Media, Tourism, Culture. London: Routledge.

Salazar NB (2005) Tourism and glocalization: "local" tour guiding. Annals of Tourism Research 32(3): 628-646.

Sandvoss C (2005) Fans: The Mirror of Consumption. Cambridge: Polity Press.

The Project on Disney (1995) Inside the Mouse: Work and Play at Disney World. Durham: Duke University Press.

Thornton S (1995) Club Cultures: Music, Media and Subcultural Capital. Cambridge: Polity Press.

Torchin L (2002) Location, location, location: the destination of the Manhattan TV Tour. Tourism Studies 2(3): 247-266.

Urry J and Larsen J (2011) The Tourist Gaze 3.0. London: Sage.

Weiler B and Ham S (2001) Perspectives and thoughts on tour guiding. In: Lockwood A and Medlik S (eds) Tourism and Hospitality in the $21^{\text {st }}$ Century. Oxford: Elsevier ButterworthHeinemann, pp. 255-264. 
Weiler B and Ham SH (2002) Tour guide training: a model for sustainable capacity building in developing countries. Journal of Sustainable Tourism 10(1): 52-69.

Zhang HQ and Chow I (2004) Application of importance-performance model in tour guides' performance: evidence from mainland Chinese outbound visitors in Hong Kong. Tourism Management 25(1): 81-91. 